\title{
CERTEZAS, DUdAS Y PROPUESTAS EN TORNO AL ESTÁNDAR DE LA PRUEBA PENAL*
}

["Certainties, Doubts and Proposals on the Standard of the Proof on Criminal Matters"]

\author{
Daniela Accatino** \\ Universidad Austral de Chile
}

\begin{abstract}
RESUMEN
El estándar de prueba más allá de toda duda razonable, que rige en el proceso penal, suscita dificultades de interpretación por su imprecisión y por su referencia a la convicción subjetiva del juzgador. El trabajo analiza esas dificultades teniendo en cuenta el papel que cumplen los estándares probatorios en la decisión sobre la prueba, las circunstancias de la aplicación del estándar más allá de toda duda razonable en los ordenamientos de "Common law" y los desafíos que ha suscitado su importación al Derecho chileno. Se desarrolla también una proposición dirigida a definir algunos criterios de suficiencia de las pruebas que permitan realizar una
\end{abstract}

\begin{abstract}
Beyond a reasonable doubt, the standard of proof ruling the criminal process raises interpretation issues due to its inaccuracy and to the reference it makes to the subjective assurance of the judge. This article analyzes said difficulties bearing in mind the role the standards of the proof play in the decision on the proof, the circumstances of the application of the standard beyond a reasonable doubt in the "Common law" systems and the challenges that have raised since it was included in the Chilean law. A proposal addressed at determining some criteria for the sufficiency of the proof that allows carrying out a justified and controlled
\end{abstract}

* Este trabajo forma parte de un proyecto de investigación que cuenta con el apoyo de FONDECYT (proyecto No 1100785). Una versión preliminar del mismo fue presentada al Seminario del Grupo de Investigación en Filosofía del Derecho de la Universidad de Gerona, dirigido por el profesor Jordi Ferrer, cuyas observaciones contribuyeron, sin duda, a mejorarlo. Agradezco también a Rodrigo Coloma los comentarios que realizara al mismo borrador.

** Profesora Asociada de la Facultad de Ciencias Jurídicas y Sociales de la Universidad Austral de Chile. Dirección postal: Facultad de Ciencias Jurídicas y Sociales, Universidad Austral de Chile, Campus Isla Teja, Valdivia, Chile. Dirección electrónica: daccatino@uach.cl 
aplicación justificada y controlable de ese estándar probatorio.

Palabras Clave

Estándar de prueba - Duda razonable - Proceso penal. application of said standard of the proof is herein developed.

\section{KEYWORDS}

Standard of proof - Reasonable doubt - Criminal process.

[RECIBIDO el 15 de noviembre y ACEPTADO el 12 de diciembre de 2011]

\section{LOS ESTÁNDARES PROBATORIOS \\ Y LA DECISIÓN SOBRE LA SUFICIENCIA DE LAS PRUEBAS}

1. Tras una larga historia de vigencia de normas de prueba tasada, la noción de "estándar de prueba" resulta todavía poco familiar en nuestra cultura legal ${ }^{1}$. Se tiende a pensar que en los actuales regímenes de libre valoración la decisión judicial sobre la prueba está sujeta sólo a exigencias de racionalidad -o, como se suele decir, de "sana crítica"-, pasando por alto, de ese modo, el papel de los estándares probatorios y de las reglas legales que los fijan. Lo cierto es, en cambio, que para decidir en forma justificada si está o no está probada en un proceso una determinada proposición sobre los hechos del caso es necesario, en un sistema de libre valoración probatoria, contar con un estándar para evaluar si las pruebas disponibles, valoradas racionalmente, son suficientes para considerarla probada. Y ese umbral de suficiencia puede ser fijado por el derecho de diversos modos, como ocurre, por ejemplo, en el caso del proceso penal chileno, con la regla que requiere respecto de la prueba de los hechos en que se funda la acusación una "convicción más allá de toda duda razonable" (artículo $340 \mathrm{CPP})^{2}$.

Para comprender el papel clave que los estándares de prueba cumplen en el juicio sobre los hechos en los sistemas procesales en los que rige el principio de libre valoración de la prueba, resulta útil diferenciar analíticamente dos momentos que integran lo que globalmente designamos como valoración de la prueba ${ }^{3}$.

${ }^{1}$ Lo mismo afirma de modo general respecto de los sistemas jurídicos de tradición continental el estudio comparativo publicado por CleRMONT, Kevin SHERwin, Emily, A Comparative View of Standards of Proof, en American Journal of Comparative Law, 50 (2002), pp. 243-275. En los sistemas de "Common law" se trata, en cambio, de un concepto extensamente utilizado.

${ }^{2}$ Cfr. Ferrer, Jordi, La prueba es libertad, pero no tanto. Una teoría de la prueba cuasi benthamiana, en AcCATino, Daniela (coordinadora), Formación y valoración de la prueba en el proceso penal (Santiago, LegalPublishing - Universidad Austral de Chile, 2010), pp. 3-19.

${ }^{3}$ La distinción entre diversos momentos de la actividad probatoria es una he- 
El primer momento, que podemos llamar el de la valoración en s e n t id o e s t r i c to, se refiere a la determinación del apoyo empírico que los elementos de prueba aportados proporcionan a las hipótesis sobre los hechos del caso que se enfrentan en el proceso. Asumiendo una concepción racional de la libre valoración, en este momento se trata de evaluar las relaciones de corroboración o confirmación que es posible establecer entre los elementos de juicio que aportan las evidencias disponibles y las proposiciones sobre los hechos del caso que son objeto del proceso, sobre la base de los conocimientos científicos de que disponemos y de las generalizaciones empíricas comúnmente aceptadas (las llamadas máximas de la experiencia).

Es importante notar que esas relaciones de corroboración se expresan como inducciones probabilísticas que no pueden demostrar la verdad de una hipótesis, sino que sólo la confirman como una explicación posible de la existencia de las evidencias valoradas, lo que por sí sólo no excluye que otras hipótesis puedan resultar igualmente explicativas ${ }^{4}$. Esto es lo que se pone de relieve cuando se dice que el juicio sobre los hechos en un proceso tiene lugar en condiciones de i n c e r $\mathrm{t}$ i d u m b r e ; una incertidumbre que, aunque es propia del razonamiento inductivo en general -y vale también, por lo tanto, tanto para la prueba de hipótesis científicas o históricas- ${ }^{5}$, se ve reforzada en el ámbito de la prueba judicial por la posibilidad de que evi-

rramienta de análisis propuesta en FERRER, Jordi, La valoración racional de la prueba (Madrid-Barcelona, Marcial Pons, 2007), pp. 41 ss.; la he utilizado antes en AcCatino, Daniela, Forma y sustancia en el razonamiento probatorio. El alcance del control sobre la valoración de la prueba a través del recurso de nulidad penal, en Revista de Derecho de la Pontificia Universidad Católica de Valparaíso, 31 (2009) 1, pp. 347-362.

${ }^{4}$ Sobre la estructura de estas relaciones de corroboración cfr. CoHEN, Jonathan, The Probable and the Provable (Oxford, Oxford U. Press, 1977), pp. 245 ss.; Gascón, Marina, Los hechos en el Derecho. Bases argumentales de la prueba (Madrid, Marcial Pons, 1999), pp. 173 ss.; Anderson, Terence - Schum, David - Twining, William, Analysis of Evidence (2a edición revisada, Cambridge, Cambridge University Press, 2005), pp. 78 ss.; Gonzalez Lagier, Daniel, Hechos y argumentos. Racionalidad epistemológica y prueb a de los hechos en el proceso pena, II, en Jueces para la democracia, 47 (2003), especialmente pp. 38 ss.; FERrer, Jordi, La valoración racional de la prueba (Madrid - Barcelona, Marcial Pons, 2007), pp. 120ss.; Accatino, Daniela, El modelo legal de justificación de los enunciados probatorios en el proceso penal y su control a través del recurso de nulidad, en LA MISMA (coordinadora), Formación y valoración de la prueba en el proceso penal (Santiago, LegalPublishing-Universidad Austral de Chile, 2010), pp. 119-143.

${ }^{5} \mathrm{Cfr}$. Popper, Karl, El desarrollo del conocimiento cientifico. Conjeturas y refutaciones (1963, traducción de Néstor Míguez, Buenos Aires, Paidos, 1994); Hempel, Carl, Filosofia de la ciencia natural (traducción de Alfredo Deaño, Madrid, Alianza, 1973), p. 36. 
dencias relevantes no lleguen a ser conocidas por el juzgador, debido tanto a las limitaciones temporales características del proceso, como a la aplicación de las reglas sobre exclusión de pruebas y a la intervención de las partes en la proposición y práctica de las pruebas ${ }^{6}$.

El resultado del momento que hemos identificado como valoración en sentido estricto consistirá, entonces, en la individualización de las pruebas que corroboran las proposiciones sobre los hechos del caso sostenidas por las partes y la identificación de los factores que inciden en su mayor o menor fuerza probatoria (las cuestiones relativas a la credibilidad o autenticidad del elemento de prueba, su carácter de prueba directa o indirecta, la validez o fundamento empírico de las generalizaciones en que se basa las inferencias probatorias), así como en la determinación de las pruebas desestimadas por su irrelevancia respecto de las proposiciones que se trata de probar o por los defectos que les restan fuerza probatoria. Dado que, por la forma inductiva del razonamiento probatorio, esas pruebas no pueden demostra r la verdad de las proposiciones fácticas que han sido objeto del proceso, sino que sólo las corroboran en menor o mayor medida, el juicio sobre los hechos supone un segundo momento, que podemos llamar de decisión sobre la prueba, en el que se trata de determinar si esas pruebas o, dicho de otra manera, el grado de corroboración que ellas aportan a las proposiciones fácticas en cuestión, es sufici en te para tenerlas por probadas. Precisar cuál es el nivel de suficiencia requerido en un determinado procedimiento es, precisamente, la tarea propia de los estándares de prueba. De este modo, los estándares de prueba determinan cuándo resulta justificado aceptar (o rechazar) una proposición fáctica en un proceso judicial, a pesar de las condiciones de incertidumbre en las que ese juicio tiene lugar.

2. Los estándares de prueba pueden ser más o menos exigentes, según si fijan un umbral mínimo de suficiencia o bien un umbral más elevado. El nivel mínimo de suficiencia es el que requiere que se tenga por probada la proposición fáctica que resulte relativamente más corroborada por las pruebas disponibles, esto es, que resulte más corroborada que las proposiciones incompatibles con ella que se hayan planteado en el proceso o, en todo caso, más corroborada que su negación. Este umbral puede considerarse "mínimo" porque un estándar menos exigente implicaría que se debiera tener por probada una hipótesis menos corroborada, o, dicho de otro modo, menos probablemente verdadera, que otras hipótesis sostenidas en el proceso, lo

${ }^{6} \mathrm{Cfr}$. Coloma, Rodrigo, Estándares de prueba y juicios por violaciones a los derechos humanos, en Revista de Derecho de la Universidad Austral de Chile, 22 (2009) 2, pp. 205-229. 
que constituiría una directiva incompatible con la exigencia de valoración r a c i o n a l de la prueba. Como dice Michele Taruffo, "sería irracional dejar que el juzgador eligiera la versión de los hechos que esté menos apoyada por los medios de prueba”. Este estándar de prueba mínimo suele conocerse como estándar de preponderancia de la prueba y corresponde al que en derecho comparado - particularmente en los sistemas de tradición anglosajona- se considera aplicable en los procesos civiles.

Pero el derecho puede fijar también un estándar de prueba más exigente, requiriendo un grado de corroboración mayor a la preponderancia relativa para que una hipótesis pueda tenerse por probada. Lo que se produce de ese modo es una distribución diferenciada del riesgo de e r r o r entre las partes de un proceso, pues al elevar el umbral de suficiencia de la prueba se reduce, por una parte, el riesgo de que se cometa un error al declarar probada una proposición fáctica (es decir, el riesgo de que se declare probada una proposición falsa o riesgo de un falso positivo), pero aumenta correlativamente, por otro lado, el riesgo de que se yerre al declarar no probada una proposición fáctica (es decir, el riesgo de que se declare no probada una proposición verdadera o falso negativo). Este efecto se aprecia con mayor claridad si se hace un contraste con lo que ocurre cuando se aplica el estándar mínimo de prueba. Bajo ese estándar el riesgo de error se distribuye igualitariamente, de modo que el riesgo de error al tener por probada en un caso una proposición, es simétrico al riesgo de error al no declararla probada, pues los dos tipos de error se producen cuando las evidencias disponibles confirman en mayor grado relativo una hipótesis que resulta falsa (el falso positivo cuando la hipótesis que se trata de probar resulta mayormente corroborada que las demás hipótesis incompatibles propuestas o que su negación y, sin embargo, es falsa; el falso negativo cuando resulta mayormente confirmada por las pruebas una hipótesis incompatible con la que se trata de probar o bien su negación). En el caso de un estándar más exigente, en cambio, disminuye el riesgo de error al declarar probada una proposición, pues se requerirá una prueba de mayor contundencia que la puramente preponderante; pero, a la vez, el riesgo de error al declarar no probada una proposición fáctica es más alto, pues aún si las pruebas disponible corroboran esa proposición en mayor grado que a su negación o a las proposiciones incompatibles que hayan sido sostenidas en el proceso, el estándar requiere que si no se satisface el umbral más alto que él fija, la proposición en cuestión se tenga por no probada.

En definitiva, los fines que subyacen a los dos estándares de prueba son diferentes. En el caso de un estándar de prueba mínimo el fin que se persigue

${ }^{7}$ TARUffo, Michele, La prueba (traducción de Laura Manríquez y Jordi Ferrer, Madrid - Barcelona, Marcial Pons, 2008), p. 138. 
es evitar en general el error al determinar los hechos en un proceso. Se trata, en este sentido, del estándar más funcional si se toma en cuenta únicamente el fin de averiguación de la verdad. Por eso puede considerarse que a falta de una regla legal que fije en forma expresa un estándar de prueba para un determinado proceso, este sería el estándar supletorio, determinado por la exigencia de racionalidad en la valoración de la prueba, que requiere, precisamente, la utilización al ponderar la prueba de los medios más idóneos para el fin de averiguar la verdad ${ }^{8}$. Cuando se adopta, en cambio, un estándar probatorio más exigente, lo que está en juego es evitar especialmente un tipo de error, el falso positivo (declarar probada una proposición falsa), aun a costa de elevar el riesgo de falsos negativos (declarar no probada una proposición verdadera). Se trata, como se puede observar, de un fin diferente al de la pura averiguación de la verdad y que está parcialmente en tensión con éste 9 . La asunción de ese fin, y su realización a través de un estándar de prueba de mayor exigencia que el de preponderancia de la prueba, supone que el error al declarar probada una proposición falsa en una determinada clase de proceso sea valorado como mayormente grave por sus costos por la comunidad política.

Esto último es lo que debiera ocurrir, de acuerdo a una concepción moral que tiene una larga tradición en Occidente, respecto de las proposiciones que integran la acusación en el caso del proceso penal, pues los costos de la condena penal errónea de un inocente, por la afectación que puede implicar de bienes fundamentales del sujeto como la libertad y la honra, justificarían que ese error se considere de mayor gravedad que el error al absolver un culpable. Esto es lo que expresarían fórmulas clásicas como las que afirman que es mejor que diez, cien o hasta mil culpables sean absueltos a que un solo inocente sea condenado injustamente (son palabras de, respectivamente, Blackstone en el siglo XVIII, Benjamin Franklin en el mismo siglo y Moisés Maimónides en el siglo XII $)^{10}$. Esta valoración diferenciada de la gravedad de los errores

${ }^{8}$ En un sentido semejante: BAyón, Juan Carlos, Epistemología, moral y prueba de los hechos: hacia un enfoque no benthamiano, ponencia presentada en el XIV Congreso ítalo-español de Teoría del Derecho [visible en internet: http://www.udg.edu/ LinkClick.aspx?fileticket $=$ fYVRM58p9Z4\%3D\&tabid $=9724 \&$ language $=$ en $-U S]$, pp. 8-10; TARuffo, Michele, Considerazioni su dubbi e verità, en Criminalia. Annuario di scienze penalistiche (2009), pp. 305-331.

${ }^{9}$ LaUdan, Larry, Por qué un estándar de prueba subjetivo y ambiguo no es un estándar, en Doxa. Cuadernos de Filosofía del Derecho, 28 (2005), pp. 96-97, lo caracteriza como un valor quasi epistémico, distinguiéndolo tanto de los valores epistémicos -la averiguación de la verdad y la minimización del error-, como de los valores extra epistémicos que son relevantes en la justificación de reglas procesales.

${ }^{10}$ Una revisión de los antecedentes históricos de esta concepción puede verse en STElla, Federico, Giustizia e modernità. La protezione delll 'inocente e la tutela delle 
en que es posible incurrir al determinar los hechos en un proceso penal justificaría, según esta concepción moral, que se intente evitar especialmente el riesgo de error al condenar, fijando un estándar de prueba especialmente exigente -más exigente, por cierto, que el de mera preponderancia de la prueba- para que puedan tenerse por probadas las proposiciones fácticas sostenidas por la acusación. Como veremos en la próxima sección, una de las pocas certezas actuales respecto al estándar de prueba más allá de toda duda razonable, que ha adoptado nuestro Código Procesal Penal, es su sustento en esta concepción ético política y su propósito de evitar especialmente el error al condenar en un proceso penal, fijando un elevado umbral de suficiencia para la prueba de la acusación.

\section{LA PARADÓJICA SITUACIÓN DEL ESTÁNDAR DE PRUEBA} “MÁS ALLÁ DE TODA DUdA RAZONABLE” EN SU CONTEXTO DE ORIGEN

1. Desde hace más de 200 años que en los sistemas jurídicos de "Common law" se utiliza la fórmula que requiere en los procesos penales que la acusación sea probada "más allá de toda duda razonable" ${ }^{11}$. Esa larga tradición ha visto renovada y reforzada su significación en la configuración del proceso penal a partir de 1970, cuando la Corte Suprema de los Estados Unidos sostuvo, en el caso "In re Winship", y luego en una extensa línea de casos posteriores, que la aplicación en todo proceso penal del estándar de prueba "más allá de toda duda razonable" resulta exigida por la cláusula constitucional del debido proceso ${ }^{12}$. Estas sentencias expresan con gran claridad el sentido que se reconoce a esa fórmula como garantía en favor del acusado, que "proporciona sustancia concreta a la presunción de inocencia" al fijar "un estándar de prueba más rigurosos que el propio de las causas civiles" 13 , reflejando "una convicción fundamental de nuestra sociedad, según la cual es mucho peor que se condene a un inocente a que un culpable quede libre"14. Con la misma

vittime ( $3^{a}$ edición, Milán, Giuffrè Editore, 2003), pp. 127-129.

${ }^{11}$ Shapiro, Barbara, Beyond reasonable Doubt and Probable Cause: Historical Perspectives on the Anglo-American Law of Evidence (Berkeley, University of California Press, 1991), especialmente pp. 22-25; Whitman, James, The Origins of Reasonable Doubt. Theological Roots of the Criminal Trial (New Haven - Londres, Yale University Press, 2008), pp. 186-200.

12 "In Re Winship" 397 U.S. 358 (1970). Otras sentencias relevantes son, por ejemplo, “Sullivan v. Louisiana”, 508 U.S. 275, 278 (1993) y “Apprendi v. New Jersey”, 530 U.S. 466, 477 (2000). Una buena síntesis de esa evolución puede verse en STELla, Federico, cit. (n.10), pp. 154-195.

${ }^{13}$ Opinion concurrente del juez Harlan en la sentencia "In Re Winship", cit. (n.12).

14 “In Re Winship”, cit. (n. 12). 
claridad esas sentencias dan cuenta del arraigo de esa convicción en el valor fundamental que se reconoce a los intereses del acusado que se ponen en juego en un proceso penal y que determinan que a su respecto el riesgo de error deba ser reducido al mínimo por la extrema gravedad de sus consecuencias: la libertad personal, la dignidad humana y la protección de la honra frente a la estigmatización que significa una condena penal, e incluso la vida, en aquellos casos en los que pudiera imponerse la pena de muerte ${ }^{15}$.

2. Paradójicamente, sin embargo, al mismo tiempo que se reconoce al estándar de prueba "más allá de toda duda razonable" ese papel decisivo para la distribución equitativa del riesgo de error en un proceso penal, en los mismos tribunales norteamericanos se ha debatido intensamente sobre la mejor forma de explicar lo que esa fórmula requiere ${ }^{16}$. Dado que el veredicto de los jurados que resuelven sobre la prueba de los hechos del caso en un proceso penal no debe ser fundamentado, la discusión se ha referido sobre todo al contenido de las instrucciones que el "trial judge" debe dar a los jurados acerca de la aplicación del estándar.

Una de las explicaciones más utilizadas tradicionalmente asimilaba el estándar más allá de toda duda razonable a una exigencia de "certeza moral". Esta equiparación, utilizada intensamente durante el siglo XIX, es interesante, porque conecta al estándar de prueba penal con una tradición epistémica, la de la filosofía empirista inglesa del signo XVII (y especialmente la versión desarrollada por Locke en An Essay Concerning Human Understanding), que podría efectivamente ofrecer un marco para una elaboración del significado de la fórmula de la duda razonable, en la medida que utilizaba la expresión "certeza moral" para designar el grado más alto de justificación al que podían aspirar las creencias sobre asuntos empíricos, en la medida que si bien no cabía respecto de ellos la certeza matemática, asociada a la demostración rigurosa, sí era posible justificar, sobre la base de pruebas contundentes, creencias capaces de imponerse con una fuerza cercana a la certeza ${ }^{17}$. Con todo, este

${ }^{15}$ Cfr. Broun, Kenneth. S. y otros, McCormick on Evidence ( 6 a edición, St. Paul, Thomson/West, 2006), p. 571; S Tella, Federico, cit. (n. 10), pp. 161-178.

${ }^{16}$ Para una síntesis de esa discusión véase Cohen, Jessica, The Reasonable Doubt Jury Instruction: Giving Meaning to a Critical concept, en American Journal of Criminal Law, 22 (1995), pp. 677-701; LAUdan, Larry, Is Reasonable Doubt Reasonable?, en Legal Theory, 9 (2003) 2, pp. 295-331; EL MISmo,Truth, Error and Criminal Law. An Essay in Legal Epistemology (Cambridge, Cambridge University Press, 2006), pp. 32 ss.; HoRvitz, María Inés - López, Julián, Derecho procesal penal chileno (Santiago, Editorial Jurídica de Chile, 2004), II, pp.158 ss.

${ }^{17}$ Cfr. Shapiro, Barbara, cit. (n. 11), pp. 1 ss. Según la autora, para Locke en los casos en que las pruebas son contundentes, "probability upon such grounds carries so 
sentido de la noción de certeza moral fue diluyéndose progresivamente en su traducción al ámbito del proceso penal, donde terminó por ser rechazada por la Corte Suprema por el riesgo de que induzca a error y haga creer a los jurados que su decisión puede basarse en sus juicios morales sobre la conducta del acusado ${ }^{18}$. A pesar de esa resistencia, la expresión sigue siendo utilizada en algunas instrucciones a los jurados, aunque entendida simplemente como equivalente a la confianza subjetiva del juzgador en la verdad de los cargos imputados al acusado ${ }^{19}$.

Igualmente resistidos han resultado otros intentos de definición, como el que equipara la prueba más allá de toda duda razonable a aquella que resulte tan convincente como para que una persona no vacile en confiar en ella y actuar sobre esa base en los asuntos importantes de su propia vida, o el que caracteriza a la duda razonable como aquella respecto de la cual pueden darse razones $^{20}$. Tan intensas han sido las discusiones en torno a la explicación del estándar en las instrucciones a los jurados que se ha asentado incluso la conclusión-sostenida por diversas cortes estatales- de que no se debe ofrecer a los jurados ninguna definición del estándar, siendo preferible dejar que la fórmula de la duda razonable "hable por sí sola"21.

much evidence with it that it naturally determines the judgment, and leaves us as Little liberty to believe or disbelieve, as demonstration does".

18 "Victor v. Nebraska", 511 U.S. 1 (1994).

${ }^{19}$ Sobre esta evolución cfr. LAUdAN, Larry, Truth, Error, cit. (n. 16), pp. 38 ss.

${ }^{20}$ En el primer caso la crítica apunta a la equiparación del grado de certeza necesario para condenar con el que requerimos para tomar decisiones respecto de asuntos propios, pues aun respecto de cuestiones importantes las personas pueden estar dispuestas a actuar en base a creencias precarias asumiendo riesgos de error que no parece equitativo en cambio asignar al acusado en un juicio penal (así, por ejemplo, en “Commonwealth v. Ferreira”, 373 Mass. 116 [1977]). En el segundo caso la explicación ha sido rechazada básicamente porque los jurados no están sujetos a la exigencia de justificar sus veredictos (así, por ejemplo, “U.S. v. Davis”, 328 F.2d 864 [1964]. Cfr., sobre ambas, LAUDAN, Truth, Error, cit. (n. 16) p. 36 ss. Con respecto a las dificultades análogas que han enfrentado otras jurisdicciones de common law al intentar precisar el contenido del estándar, cfr. Mulrine, Thomas, Reasonable Doubt: How in the World it is Defined?, en American University International Law Review, 12 (1997) 1, pp. 195225 , pp. 214 ss.

21 "U.S. v. Glass", 846 F.2d 386 [1988], cit. por LaUdan, Larry, Truth, Error, cit. (n. 16), p. 48. Algo semejante ha ocurrido también en el Reino Unido, donde tras las mismas discusiones sin fin sobre cómo explicar a los jurados el contenido del estándar, terminó por imponerse también, entre las cortes de apelación, la directriz de evitar cualquier definición. En los últimos años, sin embargo, la fórmula de la prueba más allá de toda duda razonable ha sido sustituida en las instrucciones dirigida a los jurados por una diferente, que les requiere "estar seguros" de la culpabilidad. Esta nueva formulación ha sido recomendada por el Judicial Studies 
Este último paso en la discusión sobre el estándar más allá de toda duda razonable parece llevarnos de vuelta al punto de partida, en el sentido que lo que esa fórmula puede decir hoy "por sí sola”, de manera autoevidente, parece consistir sólo en la afirmación de su sentido como garantía para el acusado. Lo dice bien Taruffo cuando afirma que "el significado central que se expresa a través de ese estándar es evidente: éste requiere un grado particularmente alto de confirmación probatoria de la culpabilidad del imputado, que se aproxima a la certeza, dado que sólo admite la presencia de dudas “irrazonables", con la evidente intención de reducir al mínimo el riesgo de condena de un inocente" 22 . Esto es, sin duda alguna, cierto e indiscutido en el contexto de origen del estándar de prueba más allá de toda duda razonable, aunque poca luz nos ofrece la experiencia de los sistemas de "Common law" sobre cómo evaluar frente a un caso concreto si las pruebas aportadas respecto de la acusación permiten considerar satisfecho ese "grado particularmente alto" de confirmación.

\section{LAS INADVERTENCIAS Y PELIGROS DE LA RECEPCIÓN EN CHILE DEL ESTÁNDAR DE PRUEBA “MÁs ALlÁ de TODA DUdA RAZONABlE”}

1. Durante la tramitación legislativa del nuevo Código Procesal Penal, que sustituiría un sistema en el que predominaba la prueba legal por uno de libre valoración de la prueba, la cuestión del estándar de prueba -o, en un lenguaje más próximo al del Código, del "grado de convicción necesario para condenar" - suscitó varias discusiones, que llevaron a que la formulación inicialmente prevista en el proyecto sufriera sucesivas modificaciones ${ }^{23}$. Originalmente el proyecto (artículo 397) establecía que "nadie podrá ser condenado por delito sino cuando el tribunal que lo juzgue hubiere adquirido

Board, a través de su "Specimen Direction" 2B, que sugiere la siguiente instrucción: "How does the prosecution succeed in proving the defendant's guilt? The answer is -by making you sure of it. Nothing less than that will do. If after considering all evidence you are sure that the defendant is guilty, you must return a veredict of 'Guilty'. If you are not sure, your veredict must be 'Not Guilty'”. Cfr., al respecto: Roberts, Paul - Zuckerman, Adrian, Criminal Evidence (2a edición, Oxford, Oxford University Press, 2010), pp. 253 ss. Podría decirse que la fórmula actual, que requiere "estar seguro", sincera la común referencia de los diversos intentos de definición del estándar de prueba más allá de toda duda razonable a un estado mental del juzgador.

${ }^{22}$ TARuffo, Michele, Simplemente la verdad. El juez y la construcción de los hechos (traducción de Daniela Accatino, Madrid-Barcelona, Marcial Pons, 2010), p. 249.

${ }^{23}$ Cfr. Pfeffer, Emilio, Código Procesal Penal anotado y concordado (Santiago, Editorial Jurídica de Chile, 2001). 
la convicción de que realmente se ha cometido un hecho punible y que en él ha correspondido al acusado una participación culpable y penada por la ley". En el Senado la formulación sufrió una primera modificación, que consistió en anteponer a la palabra convicción la expresión "suficiente", de modo de aclarar que el convencimiento al que debía llegar el tribunal no era un convencimiento absoluto ${ }^{24}$. La formulación definitiva, propuesta por la Cámara de Diputados y confirmada por la Comisión Mixta parece haber tenido un propósito semejante. Así, el "Informe de la Comisión Mixta" señaló sobre ella que "el estándar de convicción 'más allá de toda duda razonable' es propio del derecho anglosajón, y no del europeo continental, por lo que resulta una novedad también para el ordenamiento jurídico chileno. Sin embargo, es un concepto útil, toda vez que está suficientemente decantado y elimina las discusiones relativas al grado de convicción que se requiere, dejando en evidencia que no se trata de una convicción absoluta, sino de aquella que excluya las dudas más importantes" 25 .

La preocupación del Congreso por evitar que el estándar de prueba requiriera una convicción "absoluta" es sensata, pues, como hemos visto, en el razonamiento probatorio judicial -y en general cuando se trata de cuestiones empíricas- no es posible justificar racionalmente conclusiones ciertas. Con mayor razón lo es, por otra parte, si tenemos presente que la reforma procesal penal implicaba el paso de un sistema de prueba legal, que podía producir al menos una aparente certeza absoluta a través de la definición legal de "plenas pruebas" ${ }^{26}$. Desde esta perspectiva, la formulación finalmente fijada tiene efectivamente la ventaja de explicitar que una hipótesis que deba tenerse por probada puede, sin embargo, merecer algún grado de dudas.

El problema es, sin embargo, que la imprecisión del estándar no permite establecer con claridad cuál es ese grado de duda tolerable. No parece, con todo, que la relevancia de este último aspecto haya sido advertida en el contexto de la discusión parlamentaria. De hecho, la propuesta del Senado de expresar el estándar en términos de "suficiente" convicción revela desconocimiento de que la función del estándar de prueba es precisamente la de determinar cuándo los elementos de prueba son suficientes o, dicho en un estilo más próximo al del legislador, cuál es el grado de convicción suficiente. Se podría pensar que la Comisión Mixta pretendió justamente evitar esa tautología vacía cuando resolvió importar el estándar de prueba más allá de toda duda razonable, que al estar "suficientemente decantado" en la práctica

${ }^{24}$ Historia de la ley 19.696, p. 1824.

${ }^{25}$ Historia de la ley 19.696, p. 2005.

${ }^{26}$ Lo pone de relieve Riego, Cristián, Nuevo estándar de convicción (2003), ahora en Duce, M. - Riego, C., Proceso penal (Santiago, Editorial Jurídica de Chile, 2007), pp. 483-485. Vid. infra n. 43. 
judicial comparada, podría "eliminar" las discusiones relativas al "grado de convicción" requerido ${ }^{27}$. Aun si así fuera, sin embargo, se podría de todos modos imputar a la Comisión Mixta una nueva inadvertencia. Pues, como hemos visto en la anterior sección, si bien es efectivo que el sentido político del estándar como garantía del acusado se encuentra claramente asentado en su contexto de origen, la posibilidad de identificar criterios precisos de aplicación del mismo ha estado y sigue estando expuesta a intensas controversias, de modo que las condiciones de suficiencia de la prueba que impondría el estándar más allá de toda duda razonable parecen lejos de estar suficientemente decantadas. Es sorprendente que estos antecedentes no hayan sido considerados, particularmente si pensamos en las dificultades, más agudas incluso, que la imprecisión de la formulación del estándar generaría respecto de tribunales a los que al mismo tiempo se imponía la exigencia de justificar detalladamente sus decisiones sobre la prueba, no prevista en cambio en los sistemas anglosajones respecto de los jurados ${ }^{28}$.

Aunque se diga que mal de muchos es consuelo de tontos, algo puede atenuarse la responsabilidad del legislador chileno si se observa que su entusiasmo por la fórmula de la prueba más allá de toda duda razonable ha sido compartido también en otros sistemas jurídicos de tradición continental, en los que ha sido incorporada también a sus códigos de procedimiento penal -como ocurrió, por ejemplo, recientemente en Italia ${ }^{29}$ y Colombia ${ }^{30}-$, o ha sido invocada por la doctrina y la jurisprudencia para definir el nivel de prueba necesario para tener por probada la acusación en el proceso penal y superar la presunción de inocencia -como ha sido, por ejemplo, el caso en España y

${ }^{27}$ Las frases entrecomilladas son cita del informe de la Comisión reseñado antes: véase, más arriba, la n. 25.

${ }^{28}$ Cabe agregar que no se tomó en cuenta tampoco, por otra parte, la diferencia entre los contextos de reglas sobre la prueba en que en uno y otro caso -en los sistemas de "Common Law" y en el sistema procesal penal chileno- jugaría el estándar de prueba. Un punto significativo, si se piensa que en los primeros sistemas rigen reglas de exclusión de prueba y de orientación de la deliberación mucho más extensas que las usuales en los sistemas de tradición continental, que pueden atenuar en parte las consecuencias de la imprecisión del estándar, al excluir o exigir corroboración respecto de clases de pruebas cuya fuerza probatoria resulta en general difícil de establecer (por ejemplo, testimonio de oídas, testimonio de la víctima). Vid. infra n. 51.

${ }^{29}$ Modificación del artículo 533 CPP., introducida por la Ley de 20 de febrero de 2006. Véase al respecto: Conti, Carlotta, Al di là del ragionevole dubbio, en SCalfati, Adolfo (editor), Novità su impugnazioni penali e regole di giudizio. Legge 20 frebbraio 2006, n. 46 “legge Pecorella” (s/l, IPSOA-Wolter Kluwer Italia, 2006), pp. 87-117.

${ }^{30}$ Artículos 7 y 372 del Código de Procedimiento Penal colombiano (Ley No 906 de 2004). 
también en Italia, antes de su adopción legal ${ }^{31}-$. También cabe notar que la misma formulación del estándar ha sido fijada para el proceso ante la Corte Penal Internacional, por su Estatuto ${ }^{32}$.

2. Una vez que el nuevo Código Procesal Penal entró en vigencia, la cuestión de la interpretación de la exigencia de "convicción más allá de toda duda razonable" suscitó rápidamente discusiones. De los primeros trabajos dogmáticos sobre el tema, hay dos que merecen especial atención. Como veremos, ellos ilustran bien los dos peligros que entraña la fórmula utilizada por el nuevo código: por una parte, el peligro de una lectura subjetivista, que refiera el estándar a la sola existencia de un estado mental del juzgador, y, por otra parte, el peligro, que ya anticipábamos, de la imprecisión.

El primero es un texto de Julián López, en el que se emprende, en primer lugar, la tarea que durante la tramitación legislativa del Código fue omitida y se examina detenidamente la discusión abierta en Estados Unidos en torno al estándar de prueba más allá de toda duda razonable. López observa entonces que una de las interpretaciones presentes en esa controversia equipara la prueba más allá de toda duda razonable con una noción que tenía ya una "larga tradición" en nuestra práctica procesal anterior a la reforma, la de certeza moral, y defiende su adopción para facilitar la aplicación del nuevo estándar, ya que "reconduce a los jueces [...] a la utilización de parámetros a los que se encuentran habituados"33. Esa larga tradición es la que se había formado al alero del artículo 456 bis del Código de Procedimiento Penal de 1906, interpretado como una exigencia de "certeza legal condenatoria y certeza moral absolutoria" ${ }^{\text {" }}$, que pretendía morigerar el modelo de prueba legal, autorizando la absolución, aun en el caso de haber "plena prueba", si el juzgador no había adquirido "la convicción de que realmente se ha cometido un hecho punible y que en él le ha correspondido al procesado una participación culpable y penada por la ley" (la misma fórmula que, recordemos, utilizaba el proyecto inicial del nuevo Código Procesal Penal). La certeza moral era entendida entonces como el convencimiento subjetivo del juzgador acerca de la verdad de los hechos imputados por la acusación y del mismo modo la concibe también Julián López ${ }^{35}$. Lo que eso implicaba en el contexto de la

${ }^{31}$ Véanse, a título ejemplar, las sentencias del Tribunal Constitucional español números 209/2007 y 66/2009, así como las sentencias del Tribunal Supremo números 209/2002, 43/2003, 258/2003 y 24/2004.

${ }^{32}$ Artículo 66 del Estatuto de la Corte Penal Internacional.

${ }^{33}$ Horvitz, María Inés - López, Julián, cit. (n. 16), p. 164.

${ }^{34} \mathrm{Cfr}$. Morales Robles, Eduardo, Explicaciones de Derecho procesal, III: Derecho procesal penal (Santiago de Chile, impresión privada, 1987), pp. 262-263.

${ }^{35}$ Cfr. HoRvitz, María Inés - López, Julián, cit. (n. 16), pp. 162-164. Acerca de la pro- 
vieja tradición anterior a la reforma resulta bien ilustrado por dos botones de muestra. Primero, el "Mensaje" del Código de 1906, que indicaba que "si esta convicción [adquirida por los medios de prueba legal] no llega a formarse, eljuezpodráabsolversin otro fundamento y cualesquiera que sean los antecedentes que el proceso arroje contra el reo". Y luego una sentencia de la Corte Suprema de diciembre de 1997, representativa de la jurisprudencia de la época, que interpreta la expresión en cuestión como "un llamado del legislador al fuero in timo del juezy, por lo tanto (..) un concepto imponderable para alguien que no sea el destinatario directo de él"36.

Aunque es cierto que en el viejo sistema la noción de certeza moral podía servir, aún bajo esa lectura subjetivista, como válvula de moderación de la irracionalidad a la que conduce el formalismo de las reglas de prueba legal, resulta difícil comprender qué ventajas podría suponer la aplicación de esta concepción en un sistema de libre valoración -supuestamente racional y justificada- de la prueba: ¿se volvería posible, entonces, ahora, también condenar sin otro funda mento que la presencia, en el ánimo de los juzgadores, de convicción $y$ cualesquiera que sean los antecedentes que el proceso arroje?, ¿yla evaluación de esa convicción para condenar debiera considerarse ahora i m po nde rable también para otro que no fuera el decisor?

3. Desgraciadamente, las actuales prácticas judiciales de aplicación del artículo 340 confirman, en buena medida, que lo que esas preguntas sugieren es, precisamente, lo que ocurre bajo una lectura subjetivista del estándar de prueba. Si consideramos, por una parte, su aplicación en las sentencias de Tribunales de Juicio Oral, notaremos que se repite su invocación como una especie de mantra, que afirma que sobre la base de los elementos de pruebas que antes han sido identificados -o, en el mejor de los casos, analizados"valorados con libertad y sin contradecir los principios de la lógica, las máximas de la experiencia y los conocimientos científicamente afianzados, el tribunal ha adquirido la convicción, más allá de toda duda razonable, que se encuentran acreditados los siguientes hechos" ${ }^{37}$. De este modo, la aplicación del estándar se agota en la pura afirmación de la existencia de convicción del tribunal, sin que se aborde a través de una justificación reflexiva la cuestión

gresiva desconexión, en el ámbito anglosajón, del uso actual de la expresión "certeza moral" y sus orígenes filosóficos, véase: LAUDAN, LARRY, Truth, Error, cit. (n. 16), p. 35.

${ }^{36}$ Fallos del Mes 4 (1997), p. 2336.

${ }^{37} \mathrm{Cfr}$. las opiniones en el mismo sentido, reseñadas en Coloma, Rodrigo - CARBONELl, Flavia y otros, Nueve jueces entran en diálogo con nueve hipótesis acerca de la prueba de los hechos en el contexto penal, en Ius et Praxis, 16 (2010) 2, pp. 3-55. 
de la suficiencia de las pruebas. Y luego, si atendemos a las sentencias que se pronuncian sobre el alcance del control que a través del recurso de nulidad puede ejercerse sobre la fundamentación del juicio sobre los hechos [causal del artículo 374 letra e), en relación con los artículos 342 letra c) y 297 CPP.], observamos que una firme tendencia jurisprudencial excluye que la justificación de la suficiencia (o insuficiencia) de las pruebas pueda ser revisada, porque la convicción del tribunal más allá de toda duda razonable "es un asunto radicado en el fuero interno de los dirimentes llamados a conocer de una determinada materia, sin que esta Corte tenga la facultad de anular por ese motivo, el juicio que ellos han sido llamados a resolver, ya que dich a decisión emana del ámbito de su propia conciencia, previo un conocimiento exhaustivo y directo de los hechos" ${ }^{\prime 8}$.

Estas referencias ilustran como una lectura subjetivista del estándar de prueba más allá de toda duda razonable termina por privarlo de su función normativa, pues bajo esa lectura lo único que el estándar dice que: "es suficiente la prueba que el tribunal crea que es suficiente”. Ningún criterio para decidir sobre la prueba resulta fijado de esa manera, ni ningún criterio para evaluar si una decisión sobre los hechos resulta justificada ${ }^{39}$, con el resultado paradójico de que si bien se reconoce la adhesión del Código a un modelo de valoración racional o de sana crítica, y se acepta entonces que hay criterios racionales para determinar el grado o la fuerza con que los elementos de prueba corroboran las proposiciones sobre los hechos acerca de cuya prueba se discute, se deja abandonada al mismo tiempo la determinación

${ }^{38}$ Sentencia de la Corte Suprema de 13 de enero de 2005. Sobre esta tendencia, véase: Cortez Matcovich, Gonzalo, EL recurso de nulidad. Doctrina y jurisprudencia (Santiago, LexisNexis, 2006), pp. 334 ss.; Accatino, Daniela, El modelo, cit. (n. 4).

${ }^{39}$ Poniendo de relieve el mismo problema con respecto a la práctica jurídica norteamericana, Laudan, Larry, Porqué un estándar, cit. (n. 9), pp. 104-105, ha propuesto la siguiente, elocuente, comparación: "Imagínese que le dijésemos a los matemáticos que, de ahora en adelante, contarán con una prueba legítima de un teorema tan pronto como estén convencido de la verdad de dicho teorema. O, supóngase que les decimos a los epistemólogos que si están sumamente seguros de la existencia de una conexión causal entre A y B, entonces tienen una prueba de ello. Propuestas como estas serían objeto de risa. Uno no debería decirle a cualquier juzgador de los hechos: Usted ha proporcionado una prueba de A cuando esté firmemente convencido de A. (...) Al contrario, lo que le decimos es: Usted no está autorizado para estar totalmente convencido de $\mathrm{A}$ a menos que y hasta que usted tenga una prueba de $\mathrm{A}$, añadiendo para completar la propuesta que sus firmes convicciones acerca de A no cuentan en absoluto como si tuviese una prueba de A. Y entonces procederíamos a decirle cómo sería una prueba de A. Eso es lo que supone tener un estándar de prueba. Un estándar de prueba apropiado no depende de una confianza subjetiva en una hipótesis; al contrario, el estándar de prueba nos dice cuándo la confianza subjetiva está justificada" (el espaciado ha sido agregado). 
de su suficiencia para tenerlos por probados a una suerte de epifanía del juzgador, liberada de toda exigencia de justificación racional y de todo control. Terminaría así volviendo a entrar al proceso penal, por la ventana del estándar de prueba, la concepción de la libre valoración como íntima convicción que se había sacado por la puerta través de las exigencias de racionalidad y del reforzamiento del deber de fundamentar la decisión sobre los hechos que contempla el artículo $297^{40}$.

4. Pero el subjetivismo no es el único peligro que involucra el recurso a la fórmula de la convicción más allá de toda duda razonable para definir el estándar de prueba. El segundo de los trabajos pioneros referidos al tema, publicado por Cristián Riego el año 2003 y luego reeditado con modificaciones el año 2007 en un libro del que es coautor junto a Mauricio Duce ${ }^{41}$, muestra bien que aunque se pretenda interpretar el estándar a través de la identificación de "criterios menos subjetivos que resulten más susceptibles de control a través de la fundamentación del fallo" ${ }^{42}$, la indeterminación de la noción de duda razonable ofrece poco de qué asirse para su construcción. Tanto es así que, si bien ese trabajo avanza en identificar algunos tipos de dudas marginales que debieran considerarse no razonables y no debieran por tanto obstaculizar la justificación de la condena, tales como los cabos sueltos y las dudas puramente hipotéticas o imaginarias que carecen de base en la evidencia ${ }^{43}$, se reconoce a la vez que la tarea de proponer criterios

${ }^{40}$ Así lo advertía Rodrigo Coloma, Panorama general de la prueba en el juicio oral chileno, en EL MiSmo (editor), La prueba en el nuevo proceso penal (Santiago de Chile, LexisNexis, 2003), pp. 26 ss. En un sentido semejante, cfr. CERDa SAN MARTín, Rodrigo, Valoración de la prueba. Sana critica (Santiago de Chile, Librotecnia, 2008), pp. 93-102.

${ }^{41}$ Riego, Cristián, cit. (n. 26).

${ }^{42}$ Ibíd., p. 500.

${ }^{43}$ Ibíd., pp. 500-501. Volveremos sobre estas propuestas en la última parte de este artículo. Este no es, por otra parte, el único aporte del texto de Riego. También se explica en él con gran claridad la discontinuidad radical entre el contexto normativo de la decisión sobre la prueba en el antiguo y en el nuevo proceso penal, en la medida que en el primero la exigencia de plena prueba y de certeza subjetiva para la condena convivía con la desprotección del imputado en la etapa de investigación que hacía posible la obtención de confesiones que permitían satisfacer esa exigencia probatoria. De este modo se hace patente que el desafío para el nuevo proceso penal -al que el estándar de prueba más allá de toda duda razonable pretendería responder- es el de identificar criterios de suficiencia de la prueba que, aun manteniendo un umbral elevado de exigencia, no aspiren a la certeza demostrativa que resultaba (en apariencia) de las reglas de prueba legal, ni cuenten con la confesión como "reina de las pruebas". Resulta claro entonces que la recuperación de la noción de certeza moral o certeza subjetiva -uno de los engranajes del viejo contexto normativo- no resulta de gran utilidad para abordar esa tarea. 
operativos para la aplicación del estándar es "particularmente dificultosa" y que "no estamos en condiciones de ofrecer una teoría o solución conceptual consistente, aplicable de manera general a todos los casos" ${ }^{\prime 4}$.

\section{IV. ¿ALGUNA ESPERANZA PARA EL ESTÁNDAR DE PRUEBA PENAL?}

1. Las dificultades derivadas del tono subjetivista y de la falta de determinación de la fórmula de la convicción más allá de toda duda razonable parecen dejar poco espacio para la esperanza en la posibilidad de articular criterios claros de aplicación del estándar y propician propuestas de lege ferenda para el abandono de esa formulación y la redefinición del estándar de prueba en términos precisos y que eviten vincular la suficiencia de las pruebas con la convicción del juzgador ${ }^{45}$. Me parece, sin embargo, que si se toman como punto de partida las pocas certezas compartidas sobre el estándar de prueba más allá de toda duda razonable, referidas, según hemos visto, al sentido moral de la decisión subyacente sobre la distribución del riesgo de error en el proceso penal, todavía es posible realizar algunos esfuerzos para precisar las condiciones de suficiencia de la prueba que son consistentes con esa decisión. Pero antes de explorar esta posibilidad, me haré brevemente cargo de una opción diferente, defendida por Alfredo Etcheberry ${ }^{46}$.

La tesis en que se apoya la propuesta de Etcheberry es que existe, en los diversos sistemas procesales, una relación entre la regulación de la decisión sobre la prueba de los hechos y la estructura del órgano que juzga ${ }^{47}$. Eso ocurriría también, en particular, en los sistemas procesales anglosajones, con

${ }^{44}$ Ibíd., p. 498.

${ }^{45}$ Una de las voces más críticas, en este sentido, es la del destacado epistemólogo interesado en los problemas de la prueba judicial, LAUDAN, Larry, Una breve réplica, en Doxa. Cuadernos de Filosofía del Derecho, 28 (2005), p. 155, en cuya opinión: "el intento de fundamentar un estándar de prueba en la presencia o ausencia de una duda subjetiva (aunque esa duda pueda ser definida) nunca ofrecerá un estándar que sea coherente y uniforme entre los diferentes jueces y juicios". De manera semejante, FERrer, Jordi, La valoración, cit. (n. 3), p. 146, sostiene que "a falta de un criterio de razonabilidad de la duda, esta formulación del estándar de prueba penal no consigue superar los problemas señalados para la íntima convicción, que los hacen inservibles como estándares de prueba (...). Es decir, por su vaguedad extrema, no indican un umbral o nivel de suficiencia de la prueba que sea intersubjetivamente controlable".

${ }^{46}$ Etcheberry, Alfredo, Consideraciones sobre el criterio de condena en el código procesal penal, en Rodríguez Collao, Luis (coordinador), Delito, pena y proceso. Libro homenaje a la memoria del profesor Tito Solari Peralta (Santiago de Chile, Editorial Jurídica de Chile - Pontificia Universidad Católica de Valparaíso, 2008), pp. 659-678.

${ }^{47}$ Ibíd., p. 665. 
respecto al estándar de prueba más allá de toda duda razonable y la existencia de un jurado lego que no fundamenta sus veredictos y que resuelve por unanimidad. Sobre esta base, el autor afirma que al importar ese estándar a nuestro proceso penal, no se advirtió su incompatibilidad con un modelo de tribunal colegiado letrado, que puede resolver por mayoría y en el que tanto la sentencia como los votos disidentes deben ser fundamentados. La incongruencia se produciría en el caso de una decisión condenatoria adoptada por mayoría, pues si "el voto minoritario debe ser obligatoriamente fundamentado, ello es una clara muestra de que ha existido una duda razonable, a menos que califiquemos al miembro de la minoría como un juez irracional o como un juez prevaricante" ${ }^{38}$. Etcheberry asume que en un sistema que impone a los jueces la exigencia de fundamentar sus decisiones, la noción de duda razonable puede equipararse a la de $\mathrm{d} u \mathrm{~d}$ a $\mathrm{r}$ a z o n a d a, de modo que cada vez que en una sentencia condenatoria la decisión sobre la prueba se adopta por mayoría y el miembro del tribunal que no concurre a ella razona su disidencia, el estándar de prueba no debiera considerarse satisfecho. Una aplicación coherente del estándar de prueba más allá de toda duda razonable, requeriría, entonces, en el caso de un tribunal colegiado, con mayor razón si sus decisiones deben ser fundamentadas, que la decisión se adopte por unanimidad. La importación del estándar debe entonces completarse, según Etcheberry, con la adopción de la exigencia de unanimidad para la decisión de condena que rige, por regla general, en los sistemas de jurados ${ }^{49}$.

Frente a este planteamiento, cabe notar, en primer lugar, que aunque la exigencia de unanimidad para la decisión de condena en el proceso penal podría operar como garantía adicional frente al riesgo de error con respecto al acusado, su adopción no resuelve los problemas de indeterminación del estándar de prueba. Si se impusiera esa regla de decisión y toda sentencia de condena afirmara entonces razonada y unánimemente la ausencia de dudas, todavía quedaría abierta, sin embargo, la pregunta acerca de la corrección de esa decisión unánime y la bondad de las razones que ella expresa, es decir, acerca de si efectivamente en el caso la prueba es suficiente más allá de toda duda razonable. En otras palabras, seguiría abierta la cuestión de si esa condena que afirma unánime y razonadamente la ausencia de dudas está bien razonada (y, recíprocamente, si en caso de absolución, la duda unánimemente razonada, está bien razonada).

2. Ahora bien, esta elusión de los problemas de indeterminación del estándar de prueba más allá de toda duda razonable puede ser vista como parte de

${ }^{48}$ Ibíd., p. 677.
${ }^{49}$ Ibíd., p. 678. 
una estrategia posible frente a ellos. La estrategia consiste en dejar de tratar de precisar qué es lo que requiere ese estándar, en renunciar a la dificultosa búsqueda de criterios precisos de suficiencia de la prueba que determinen su contenido, para concentrar los esfuerzos en el logro del fin que a través de ese estándar se pretende realizar -una distribución diferenciada del riesgo de error, que reduzca especialmente el riesgo de condenas penales erróneas- a través de otros medios. Otros medios como la exigencia de unanimidad para la decisión de condena, propuesta por Etcheberry.

Esta estrategia de eludir la indeterminación del estándar de prueba y buscar la distribución diferenciada del error por otros medios corresponde, en buena medida, a la forma en que han operado tradicionalmente los sistemas jurídicos anglosajones. Ya hemos visto que en la discusión acerca de cómo debía instruirse a los jurados sobre el contenido del estándar ha ganado fuerza la idea de que deben evitarse las explicaciones sofisticadas y que basta su pura mención. Ahora interesa poner de relieve que en esos sistemas existe también un conjunto de reglas especiales de prueba, que limitan la admisibilidad de ciertas pruebas -el testimonio de oídas y, en general, las pruebas que puedan ser sobrevaloradas, causando un prejuicio en el juzgador- o condicionan el valor de ciertos elementos de prueba -como la declaración del coimputado, por ejemplo- a la existencia de otro medio de prueba que corrobore la información que de ellos resultaría. Este conjunto de reglas, unidas a la imposición a la parte acusadora de la carga de la prueba, actúan en el proceso penal como protecciones para el acusado frente al riesgo de error y realizan, por lo tanto, una asignación diferenciada del mismo ${ }^{50}$.

En estos sistemas, sin embargo, la elusión de la cuestión de la indeterminación del estándar de prueba se facilita porque la decisión sobre la prueba de los hechos del caso no es, como sabemos, por regla general, motivada. En los sistemas como el nuestro, en los que el juicio sobre los hechos también debe ser justificado, eludir esa cuestión es, en cambio, imposible: si el tribunal debe justificar su decisión, lo que debe justificar es precisamente la conclusión de que los medios de prueba aportados son suficientes para considerar

${ }^{50}$ Sobre la forma en que estas reglas operan como técnicas de distribución del riesgo de error, véase: STEIn, Alex, Foundations of Evidence Law (Oxford, Oxford University Press, 2005), pp. 133-140 y, críticamente, LaUdan, Larry, cit. (n. 16), pp. 117 ss. Una defensa de la existencia de estas reglas, dada la dificultad de precisar condiciones intersubjetivamente controlables de suficiencia de las pruebas que doten de contenido al estándar de prueba, puede verse en BAYón, Juan Carlos, cit. (n. 8); y en Hernández, Héctor, Pertinencia como garantía: prevención del prejuicio en el examen de admisibilidad de la prueba, en AcCATINo, Daniela (coordinadora), Formación y valoración de la prueba en el proceso penal (Santiago Legal Publishing, 2010, pp. 21-44. 
probadas ciertas proposiciones fácticas y para ello, dadas las condiciones de incertidumbre en que tiene lugar ese juicio, requiere contar con criterios de suficiencia definidos por un estándar de prueba. Sin precisión del estándar, no se puede fundamentar adecuadamente la decisión sobre la prueba, ni tampoco controlar la adecuada fundamentación de la decisión sobre la prueba.

No se trata, por supuesto, de descartar anticipadamente a través de este argumento que la estrategia de eludir la determinación del contenido del estándar de prueba e incorporar otras reglas probatorias (de admisibilidad, de corroboración y de decisión) dirigidas a evitar especialmente el riesgo de condenas erróneas permita obtener mejores resultados, sino de poner de relieve que nuestro sistema probatorio responde a un modelo diferente ${ }^{51}$, que se basa en el supuesto de que el fin de averiguación de la verdad puede lograrse de mejor manera si el juzgador puede acceder a todas las pruebas potencialmente relevantes (sin exclusiones fundadas en la posibilidad de sobrevaloración) y que confía sobre todo en la fundamentación de las decisiones sobre la prueba como garantía y herramienta de control de su racionalidad y su corrección de acuerdo a los estándares probatorios fijados por el derecho ${ }^{52}$. Antes de proponer un cambio sustancial de modelo, vale la pena, me parece, tomarse en serio esa garantía y agotar los esfuerzos para identificar criterios de suficiencia de las pruebas que precisen el contenido del estándar de prueba más allá de toda duda razonable.

\section{UNA PROPUESTA DE ARTICULACIÓN DE CRITERIOS DE} SUFICIENCIA DE LA PRUEBA QUE PRECISEN EL ESTÁNDAR DE PRUEBA MÁS ALLÁ DE TODA DUdA RAZONABLE

1. Para avanzar en la determinación del contenido del estándar de prueba más allá de toda duda razonable, el primer paso necesario consiste en evitar la interpretación subjetivista, de modo que quede claro que la aplicación del estándar no requiere una profunda introspección del juzgador para sondear

${ }^{51}$ Sobre la distinción entre modelos probatorios de "orientación profiláctica" y modelos probatorios de control a posteriori, cfr. DAMASKa, Mirjam, Evidence Law Adrift (New Haven, Yale University Press, 1997), pp. 7-25; y Accatino, Daniela, El modelo, cit. (n. 4), p. 121.

${ }^{52}$ Desde esta perspectiva se puede observar que bajo este modelo no hay, como sostenía Etcheberry, contradicción entre el estándar de prueba más allá de toda duda razonable y la regla de decisión por mayoría, pues es conceptualmente posible, en caso de disidencia, que la opinión del magistrado que no concurre a la decisión, sin ser ni "irracional" ni "prevaricante", se apoye en razones erróneas que representan una aplicación incorrecta del estándar de prueba. 
la intensidad de su convicción, sino que supone atender a la ca lidad de las pruebas disponibles.

Es cierto que el uso, en el artículo 340 CPP., de la expresión "convicción" parece sugerir que lo relevante es la presencia de hecho en el juzgador de una creencia libre de dudas; sin embargo, la referencia a dudas "razonables" admite, a mi juicio, un sentido normativo (o contra fáctico) conforme al cual lo relevante no sea la presencia o ausencia subjetiva de dudas, sino la presencia o ausencia en el conjunto de elementos de prueba disponibles de condiciones que justifican una d u d a. Lo relevante, entonces, no sería la existencia efectiva de una duda, sino la existencia en las pruebas de condiciones que justifican una duda: en otras palabras, lo que importa no es que la duda se presente de hecho en el ánimo del juzgador, sino que la duda haya de bid o suscit a rse a la luz de las evidencias disponibles.

Esta interpretación puede defenderse como sistemáticamente coherente, tanto con la exigencia legal de que la decisión sobre los hechos sea justificada por referencia a las pruebas aportadas al proceso, como con otros usos jurídicos de la expresión razonable para referir a algún tipo de estándar objetivable $^{53}$. Por otra parte, esta reformulación, al identificar duda razonable con c u a lq u i e r duda sobre la ocurrencia del hecho punible o la participación culpable del acusado que pueda justificarse en defectos de las pruebas disponibles, parece consistente con la asunción de que: $i$ ) el estándar de prueba penal debe ser especialmente exigente, para evitar en la mayor medida posible la condena de un inocente; y ii) el estándar más allá de toda duda razonable expresa esa alto grado de exigencia. Esta asunción sobre el sentido moral o político de la decisión sobre la distribución del riesgo de error que subyace al estándar de prueba más allá de toda duda razonable es compartida, según se ha visto en una sección anterior de este trabajo, en los sistemas procesales en que es utilizada. De hecho, según hemos visto, en la cultura anglosajona que sirvió de inspiración a nuestro legislador lo único que parece estar "suficientemente decantado" y no sujeto a discusión es precisamente esta asunción sobre la concepción moral subyacente al estándar ${ }^{54}$. Por último,

\footnotetext{
${ }^{53} \mathrm{Cfr}$. al respecto MacCormick, Neil, Razonabilidad y objetividad, en Revista de Ciencias Sociales, 45 (2000), pp. 399-436.

${ }^{54}$ Esta asunción política puede, evidentemente, ser objeto de discusión, por ejemplo para considerar si efectivamente es adecuado establecer un estándar de prueba exigente respecto de toda clase de delitos, con independencia de los bienes jurídicos protegidos y de las penas que se les imputen (propuestas de diferenciación en este sentido pueden verse en Lilleuist, Erik, Recasting Reasonable Doubt: Decision Theory and the Virtues of Variability, en U. C. Davis Law Review, 36 (2002) 1, pp. 85-197, pp. 147 ss.; y LaUdan, Larry, Truth, Error, cit. [n. 16]). Pero no me parece que la interpretación
} 
en la medida que la reformulación propuesta del estándar más allá de toda duda razonable considera como tal sola me n te a alguna duda sobre la ocurrencia del hecho punible o la participación culpable del acusado que pueda justificarse en defectos de las pruebas disponibles, ella es consistente con la preocupación expresada durante la discusión legislativa del proyecto de Código Procesal Penal en el sentido de que el estándar no podía requerir una "certeza absoluta", sino sólo la exclusión de dudas "importantes".

Este primer paso interpretativo permitiría reformular la disposición legal que prevé el estándar más allá de toda duda razonable, a fin de facilitar su aplicación, en los siguientes términos: "Nadie podrá ser condenado por delitosi las pruebas disponibles justifican alguna duda de que realmente se hubiere cometido el hecho punible objeto de la acusación y de que en él hubiere correspondido al acusado una participación culpable y penada por la ley".

2. Ahora bien, para que el estándar de prueba más allá de toda duda razonable pueda cumplir su papel clave en la justificación de la decisión sobre los hechos no basta que se interprete en términos objetivos (esto es, que se entienda referido a la calidad de las pruebas y no a las creencias subjetivas del juzgador), sino que se requiere además que su interpretación determine con precisión las condiciones que debe satisfacer la prueba de cargo para ser suficiente y justificar la condena. La utilidad de la interpretación propuesta para hacer operativo el estándar de prueba penal depende, entonces, de que sea posible identificar con precisión qué condiciones presentes en el conjunto de evidencias disponibles justifican una duda (o, dicho a contrario, qué condiciones deben ser superadas por las pruebas disponibles para que pueda ser justificado tener por probada la versión de los hechos de la acusación).

En primer lugar es importante distinguir estas dudas de aquellas que no se justifican en la calidad de las pruebas disponibles a favor de las proposiciones fácticas en que se funda la acusación, sino que se derivan del carácter probabilístico de la prueba judicial o del carácter normalmente fragmentario de las pruebas disponibles. El primer aspecto hace imposible descartar por completo que "las cosas no hayan podido ocurrir de otro modo", mientras el segundo hace que generalmente no sea posible reconstruir todos los detalles del modo en que se asume que ocurrieron los hechos. Esta clase de dudas -la posibilidad puramente hipotética y no sustentada en pruebas de una versión alternativa de los hechos, cabos sueltos que no se refieren al núcleo de los

del estándar de prueba más allá de toda duda razonable pueda desligarse de ella, para, por ejemplo, proponer por vía interpretativa su aplicación diferenciada, con diferentes niveles de exigencia, de acuerdo al tipo de delitos y a la penalidad prevista. Esta última cuestión requeriría a mi juicio una modificación legislativa del estándar. 
facta probanda principales, o falta de determinación de aspectos secundarios de la reconstrucción de los hechos del caso- serían las que en la tramitación legislativa de la reforma se nuevo Código Procesal Penal se calificaban, como se recordaba poco antes, como "no importantes" y por consiguiente irrelevantes para la justificación de una condena.

Para diferenciar estas dudas irrelevantes de las dudas relevantes o justificadas en las pruebas disponibles, es útil caracterizar a estas últimas como dudas justificadas en d e fectos de las pruebas disponibles en rela ción con las proposiciones fácticas que se trata de probar. De este modo resulta claro que el carácter inductivo o probabilístico de la relación entre un elemento probatorio y una proposición fáctica que se trata de probar no es un defecto de esa prueba, sino un rasgo distintivo del razonamiento probatorio ${ }^{55}$. Por otra parte, en el caso de los cabos sueltos o lagunas relativas a algún detalle de la forma en que habrían ocurrido los hechos, la falta de prueba o la existencia de contradicciones entre la información que las pruebas proporcionan no constituye un defecto de la evidencia en relación con las proposiciones fácticas a probar, en la medida que los detalles a los que se refieren no integren el núcleo de proposiciones principales, es decir, de proposiciones que son relevantes para justificar la aplicación al caso de las normas jurídicas invocadas por la acusación.

3. La distinción entre dudas irrelevantes y dudas justificadas en las pruebas disponibles no aclara, sin embargo, suficientemente, cómo se identifican estas últimas, esto es, cuáles son los "defectos" de los que puede adolecer la prueba aportada respecto de alguna proposición fáctica y que justificarían el no tenerla por probada en un proceso penal. Antes de proponer una respuesta, es necesario realizar algunas advertencias y distinciones.

En primer lugar hay que advertir que para evaluar la suficiencia de la prueba y determinar si ella es defectuosa es necesario realizar un análisis diferenciado de las pruebas disponibles respecto de cada una de las circunstancias de hecho que ha sido objeto de prueba en el proceso y que es relevante para la aplicación de la teoría jurídica en que se funda la acusación. La suficiencia de las pruebas no puede ser evaluada de modo global respecto de la historia o teoría del caso propuesta por la acusación, pues podría bastar que alguna de las circunstancias de hecho que la integra no se encontrara suficientemente probada - por ejemplo, las proposiciones fácticas que den cuenta de

${ }^{55}$ Lo destacan también Roberts, Paul y Zuckerman, Adrian, cit. (n. 21), p. 260, cuando afirman que la posibilidad meramente teórica de que una hipótesis sustentada en pruebas sea falsa no puede ser relevante en el razonamiento judicial, pues ella sólo replantea la trillada verdad de que ninguna inferencia acerca del mundo físico (ni siquiera sobre nuestra existencia) permite justificar conclusiones absolutamente ciertas. 
la participación del acusado- para que resultara justificada la absolución. Es obvio que la integración del conjunto de proposiciones fácticas sostenidas por la acusación en un relato global coherente es necesaria para que sea posible comprenderlas e interpretarlas, pero c a d a $\mathrm{u}$ n a de ellas debe estar sustentada por suficientes pruebas para poder ser tenida como probada. También es obvio, por supuesto, que un mismo elemento de prueba puede ser relevante respecto de más de una proposición fáctica principal: de lo que se trata es precisamente de identificar en forma analítica cada una de esas líneas de corroboración, para evaluar separadamente los diversos factores que pueden influir en su fuerza.

En segundo lugar, es preciso notar que una vez identificadas las pruebas disponibles respecto de cada proposición fáctica principal -agotado, esto es, el momento de la valoración de las pruebas en sentido estricto ${ }^{56}$ - podemos encontrarnos en dos situaciones que es posible distinguir y que designaré, siguiendo a Taruffo ${ }^{57}$, como "prueba convergente" y "prueba divergente".

En el primer caso, nos encontraremos con una o más pruebas que corroboran una misma proposición fáctica; por ejemplo, respecto de la proposición que afirma que fue el acusado quien cometió el asalto a una joyería, se cuenta con la declaración de un testigo que lo reconoce y con una filmación captada por la cámara de seguridad de la joyería el día del asalto, en la que aparece el acusado empuñando una pistola. La convergencia de las pruebas no excluye, sin embargo, que puedan presentarse dificultades al evaluar su suficiencia, pues la defensa puede haber discutido en el proceso la credibilidad o autenticidad de esas pruebas (e incluso pueden haberse presentado pruebas auxiliares relativas a esa falta de credibilidad o de autenticidad).

En el segundo caso nos encontramos frente a pruebas que están en conflicto entre sí, pues unas confirman la proposición sostenida por la acusación y otras en cambio la niegan, o, dicho más precisamente, confirman la negación de la proposición fáctica que se trata de probar o bien confirman una proposición distinta aunque incompatible con aquélla; por ejemplo, siguiendo con la proposición relativa a la participación del acusado como autor del asalto a una joyería, se cuenta por una parte con la declaración de un testigo que lo reconoce y con la filmación que lo muestra empuñando un arma el día del asalto, pero al mismo tiempo la defensa presenta el testimonio del dueño de un restaurant en Nueva York que declara que el acusado estaba trabajando ahí el día del asalto, así como una filmación de la cámara de seguridad del restaurant que muestra al acusado trabajando allí. Una

${ }^{56}$ Véase más arriba.

${ }^{57}$ Cfr. Taruffo, Michele, La prueba de los hechos (1992) (traducción de Jordi Ferrer, Madrid, Editorial Trotta, 2009), pp. 282-292. 
segunda situación de divergencia se puede presentar cuando las pruebas no están en conflicto entre sí, sino que corroboran o son consistentes con dos proposiciones fácticas incompatibles. Es lo que ocurriría en el caso del asalto a la joyería si se contara con la declaración del testigo que reconoce al acusado y con la filmación de la cámara de seguridad de la joyería y esas pruebas pudieran corroborar no sólo la proposición afirmada por la acusación sobre la participación del acusado como autor del asalto, sino también la hipótesis incompatible afirmada por la defensa según la cual el acusado intentó repeler el asalto con el arma que portaba.

Hechas estas aclaraciones previas, la tesis que quisiera sostener es que los defectos de las pruebas disponibles respecto de una cierta proposición sobre los hechos del caso que justifican una duda e impiden tenerla por probada bajo el estándar de prueba más allá de toda duda razonable, consisten en que ellas no logren eliminar o refutar alguna proposición fáctica alternativa plausible y compatible con la inocencia del acusado. Una interpretación semejante del estándar de prueba más allá de toda duda razonable ha sido sostenida por Michele Taruffo en Italia y por Paul Roberts y Adrian Zuckerman en el Reino Unido ${ }^{58}$. Un criterio semejante ha sido aplicado también en algunas sentencias absolutorias de Tribunales de Juicio Oral en lo Penal' ${ }^{59}$.

En la formulación que propongo se precisa que el descarte por la acusación de las hipótesis alternativas con respecto a alguna circunstancia de hecho puede realizarse, según el tipo de situación probatoria de que se trate, de dos formas diferentes, que corresponden a dos tipos de razonamiento probatorio: la eliminación y la refutación. La e li m in a c i ón opera a través de la

${ }^{58}$ Taruffo, Michele, Considerazioni, cit. (n. 8), sostiene que "existe una duda razonable cuando, frente a la descripción del hecho en que se funda la culpabilidad, es posible sin embargo afirmar una hipótesis alternativa razonable con respecto al mismo hecho". De acuerdo con Roberts, Paul - Zuckerman, Adrian, cit. (n. 21), p. 258, el estándar de prueba más allá de toda duda razonable debiera aplicarse "a través de la progresiva eliminación de las explicaciones consistentes con la inocencia del acusado, hasta que su culpabilidad sea la única explicación posible de las pruebas". Otros autores también han hecho referencia a un criterio similar para la formulación de un estándar de prueba garantista en el proceso penal, aunque sin proponerlo como interpretación del estándar más allá de toda duda razonable: cfr., por ejemplo: Allen, Ronald, Factual Ambiguity and a Theory of Evidence, en Northwestern University Law Review, 88 (1994), p. 604; STEIN, Alex, Foundations. cit. (n. 50), p. 178; FERRER, Jordi, La valoración, cit. (n. 3), pp. 147-152.

${ }^{59}$ Véanse las sentencias analizadas en Fuentes, Claudio, El manejo de la incertidumbre judicial: la construcción de la duda razonable en el sistema procesal penal, trabajo presentado al Congreso Internacional Diez Años de la Reforma Procesal Penal, organizado por CEJ America [visible en internet http://www.cejamericas.org/portal/index. php?option=com_content\&view $=$ article\&id $=761]$ 
incorporación de una nueva prueba que no resulta explicable por la hipótesis alternativa ${ }^{60}$, en situaciones de pruebas divergentes que no están en conflicto entre sí. Así en el caso del asalto a la joyería, la hipótesis alternativa, que afirma que el acusado intentó repeler el asalto con el arma que portaba, resultaría eliminada si en la filmación se observa al acusado apuntando la pistola al dueño de la joyería y recibiendo las joyas que entrega. La r e fu t a c i ó n opera en cambio a través de la incorporación de una prueba que muestra que no ocurrió un evento que debió tener lugar si es que la hipótesis alternativa fuera verdadera $^{61}$,y resulta aplicable tanto en caso de pruebas divergentes como en caso de pruebas en conflicto. Así, por ejemplo, de nuevo en nuestro caso de asalto a una joyería, en la versión que supone que se ha presentado también en juicio la declaración del dueño del restaurant en Nueva York donde el acusado habría trabajado el día del asalto y una filmación del mismo en la que aparece trabajando el acusado, esta hipótesis alternativa resultaría refutada a través de una prueba consistente en un informe de policía internacional que muestre que el acusado había salido de Estados Unidos diez días antes de la fecha en cuestión y no había vuelto a ingresar.

También en el caso de prueba convergente respecto de una determinada proposición sobre los hechos del caso, la satisfacción del estándar de prueba más allá de toda duda razonable requiere que la acusación descarte la concurrencia de el o los motivos en los que la defensa haya fundado su falta de credibilidad o de autenticidad.

Por último, en todos estos casos, las hipótesis alternativas que es necesario refutar o eliminar son las hipótesis plausibles a la luz de los actuales conocimientos generales acerca del mundo y de los datos disponibles sobre el caso, que no se presenten como hipótesis ad hoc, esto es, como hipótesis diseñadas especialmente para dar cuenta de las pruebas disponibles y para no estar expuestas a eliminación o refutación (como ocurre, por ejemplo, con la hipótesis de un complot) ${ }^{62}$.

Seguramente podrían distinguirse más tipos de situaciones probatorias para precisar cómo impone en cada una de ellas el estándar de prueba más allá de toda duda razonable la carga a la parte acusadora de aportar prueba capaz

\footnotetext{
${ }^{60}$ Sobre la eliminación de hipótesis cfr. Ferrer, J., La valoración, cit. (n. 3), p. 138.

${ }^{61}$ Sobre el esquema argumentativo de la refutación, que puede demostrar por modus tollens la falsedad de la hipótesis alternativa, siempre que sean verdaderas las generalizaciones empíricas en que se funda la predicción de que el hecho en cuestión debió ocurrir, así como el cumplimiento de las condiciones iniciales supuestas, cfr. FERRAJOLI, Luigi, Derecho y razón. Teoría del garantismo penal (traducción al castellano de Perfecto Andrés y otros, Madrid, Trotta, 1995), pp. 142 ss.; y Accatino, Daniela, El modelo, cit. (n. 4), p. 129.

${ }^{62}$ Véase al respecto: FERRER, Jordi, La valoración, cit. (n. 3), pp. 148-150.
} 
de eliminar o refutar cualquier hipótesis alternativa sobre las circunstancia de hecho del caso que resulte compatible con la inocencia del acusado. Espero que este primer paso sirva al menos para recuperar la esperanza de que, aunque no podamos contar con certezas matemáticas, sí podamos saber al menos de qué hablamos cuando hablamos de prueba más allá de toda duda razonable.

\section{BiBLIOGRAFÍA}

Accatino, Daniela, El modelo legal de justificación de los enunciados probatorios en el proceso penal y su control a través del recurso de nulidad, en LA Misma (coordinadora), Formación y valoración de la prueba en el proceso penal (LegalPublishing-Universidad Austral de Chile, Santiago, 2010).

Accatino, Daniela, Forma y sustancia en el razonamiento probatorio. El alcance del control sobre la valoración de la prueba a través del recurso de nulidad penal, en Revista de Derecho de la Pontificia Universidad Católica de Valparaíso, 31 (2009) 1.

AcCatino, Daniela, La aceptabilidad de los enunciados empíricos en el proceso penal', en Fernández, José Angel (editor), Estudios de Ciencias Penales. Hacia una Racionalización del Derecho Penal (LegalPublishing, Santiago, 2008).

Allen, Ronald J. y PARdo, Michael S. (2007): "Probability, explanation and inference: a reply", en Internacional Journal of Evidence and Proof, 11 (2007).

Allen, Ronald J., Factual ambiguity and a theory of evidence, en Nortwestern University law Review, 88 (1994).

Anderson, Terence, Schum, David y Twining, William, Analysis of evidence (2a edición revisada, Cambridge, Cambridge University Press, 2005).

BAyón, Juan Carlos, Epistemología, moral y prueba de los hechos: hacia un enfoque no benthamiano, ponencia presentada en el XIV Congreso ítalo-español de Teoría del Derecho [visible en internet: http://www.udg.edu/LinkClick.aspx?fileticket=fYV RM58p9Z4\%3D\&tabid=9724\&language $=$ en-US].

Broun, Kenneth S. et al., McCormick on evidence ( $6^{a}$ edición, St. Paul, Thomson/ West, 2006).

Carocca, Alex, El nuevo sistema procesal penal (Santiago, Editorial Jurídica La Ley, 2003).

Cerda San Martín, Rodrigo, Valoración de la prueba. Sana crítica (Santiago de Chile, Librotecnia, 2008).

Clermont, Kevin y Sherwin, Emily, A comparative view of standards of proof, en American Journal of Comparative Law, 50 (2002).

CoHen, Jessica, The reasonable doubt jury instruction: giving meaning to a criticial concept, en American Journal of Criminal Law, 22 (1995).

Cohen, Jonathan, The probable and the provable (Oxford, Oxford U. Press, 1977).

Coloma, Rodrigo, CARbonell, Flavia et Al., Nueve jueces entran en diálogo con nueve hipótesis acerca de la prueba de los hechos en el contexto penal, en Ius et Praxis, $16(2010) 2$.

Coloma, Rodrigo, Panorama general de la prueba en el juicio oral chileno, en EL mismo (editor), La prueba en el nuevo proceso penal (Santiago de Chile, LexisNexis, 2003).

Coloma, Rodrigo, Estándares de prueba y juicios por violaciones a los derechos humanos, en Revista de Derecho de la Universidad Austral de Chile, XXII (2009) 2. 
Cortez Matcovich, Gonzalo, EL recurso de nulidad. Doctrina y jurisprudencia, LexisNexis, Santiago de Chile, 2006).

Damaska, Mirjam, Evidence law adrift (Yale, Yale University Press, 1997).

Etcheberry, Alfredo, Consideraciones sobre el criterio de condena en el código procesal penal, en Rodríguez Collao, Luis (coordinador), Delito, pena y proceso. Libro homenaje a la memoria del profesor Tito Solari Peralta (Santiago de Chile, Editorial Jurídica de Chile / Pontificia Universidad Católica de Valparaíso, 2008).

FERRER, Jordi, La prueba es libertad, pero no tanto. Una teoría de la prueba cuasi bethamiana, en Accatino, Daniela (coordinadora), Formación y valoración de la prueba en el proceso penal (LegalPublishing-Universidad Austral de Chile, Santiago de Chile, 2010).

FERRER, Jordi, La valoración racional de la prueba (Madrid - Barcelona, Marcial Pons, 2007).

Fuentes, Claudio, El manejo de la incertidumbre judicial: la construcción de la duda razonable en el sistema procesal penal, trabajo presentado al Congreso Internacional Diez Años de la Reforma Procesal Penal, organizado por CEJ America [visible en internet http://www.cejamericas.org/portal/index.php?option=com content\&view $=$ article\&id $=761]$.

GASCón, Marina, Los hechos en el derecho. Bases argumentales de la prueba (Madrid, Marcial Pons, 1999).

Gascón, Marina, Sobre la posibilidad de formular estándares de prueba objetivos, en Doxa. Cuadernos de Filosofía del Derecho, 28 (2005).

Gonzalez Lagier, Daniel, Hechos y argumentos (Racionalidad epistemológica y prueba de los hechos en el proceso penal II, en Jueces para la democracia, 47 (2003).

Hempel, Carl G., Filosofía de la ciencia natural (traducción de Alfredo Deaño, Madrid, Alianza, 1973).

Hernández, Héctor, Pertinencia como garantía: prevención del prejuicio en el examen de admisibilidad de la prueba, en Accatino, Daniela (coordinadora), Formación y valoración de la prueba en el proceso penal, Legal Publishing, Santiago de Chile, 2010.

Historia de la ley 19.696 [visible en internet: http://www.bcn.cl/histley/lfs/hdl-19696/ HL19696.pdf].

HoRvitz, María Inés y López Julián, Derecho procesal penal chileno (Santiago, Editorial Jurídica de Chile, 2004), II.

LAUDAN, Larry, Is reasonable doubt reasonable?, en Legal Theory, 9 (2003) 2.

LAUdan, Larry, Por qué un estándar de prueba subjetivo y ambiguo no es un estándar, en Doxa. Cuadernos de Filosofia del Derecho, 28 (2005).

LAUdAn, Larry, Truth, error and criminal law. An essay in legal epistemology, Cambridge, Cambridge University Press, 2006).

Laudan, Larry, Una breve réplica, en Doxa. Cuadernos de Filosofia del Derecho, 28 (2005).

Lillquist, Erik, Recasting Reasonable Doubt: Decision Theory and the Virtues of variability, en U. C. Davis Law Review, 36 (2002) 1.

MacCormick, Neil, Razonabilidad y objetividad, en Revista de Ciencias Sociales, 45 (2000).

Morales Robles, Eduardo, Explicaciones de derecho procesal. Tomo III: Derecho procesal penal (Santiago de Chile, impresión privada, 1987). 
Mulrine, Thomas, Reasonable doubt: how in the world it is defined?, en American University International Law Review, 12 (1997) 1.

Nance, Dale, The weights of evidence, en Episteme: A Journal of Social Epistemology, 5 (2008) 3.

Pfeffer, Emilio, Código Procesal Penal anotado y concordado (Santiago, Editorial Jurídica de Chile, 2001).

Popper, Karl, El desarrollo del conocimiento cientifico. Conjeturas y refutaciones (1963) (traducción de Néstor Míguez, Buenos Aires, Paidos, 1994).

Riego, Cristián, Nuevo estándar de convicción (2003), ahora en Duce, M. y Riego, C., Proceso penal (Santiago, Editorial Jurídica de Chile, 2007).

Roberts, Paul y Zuckerman, Adrian, Criminal Evidence (2a edición, Oxford, Oxford University Press, 2010).

Shapiro, Barbara, Beyond reasonable doubt and probable cause: Historical perspectives on the anglo-american law of evidence (Berkeley, University of California Press, 1991).

Stein, Alex, Foundations of evidence law (Oxford, Oxford University Press, 2005).

Stella, Federico, Giustizia e modernità. La protezione delll 'inocente e la tutela delle vittime ( $3^{a}$ edición, Milán, Giuffrè Editore, 2003).

TARuffo, Michele, Considerazioni su dubbi e verità, en Criminalia. Annuario di Scienze Penalistiche (2009).

TARuffo, Michele, La prueba (traducción de Laura Manríquez y Jordi Ferrer, Madrid-Barcelona, Marcial Pons, 2008).

TARuffo, Michele, La prueba de los hechos (1992) (traducción de Jordi Ferrer, Madrid, Editorial Trotta, 2009).

TARuffo, Michele, Simplemente la verdad. El juez y la construcción de los hechos (traducción de Daniela Accatino, Madrid - Barcelona, Marcial Pons, 2010).

TARUfFo, Michele, Tres observaciones sobre 'Por quéun estándar deprueba subjetivo y ambiguo no es un estándar', en Doxa. Cuadernos de Filosofía del Derecho, 28 (2005).

Whitman, James, The origins of reasonable doubt. Theological roots of the criminal trial (New Haven - Londres, Yale University Press, 2008). 
